\title{
Nurse Readiness in Disaster Preparedness During Pandemic Covid-19
}

\author{
Putra Agina Widyaswara Suwaryo ${ }^{1}$, Sarwono $^{2}$, Hendri Tamara Yuda ${ }^{3}$ \\ ${ }^{1,2,3}$ Faculty of Health Science, Universitas Muhammadiyah Gombong
}

\begin{tabular}{l} 
ARTICLE INFO \\
\hline Article history: \\
DOI: \\
$\underline{10.30595 / p s h m s . v 2 i .238}$
\end{tabular}

Submitted:

December 6, 2021.

Accepted:

January 21, 2022

Published:

January 26, 2022

\section{Keywords:}

Knowledge; Nurse Readiness; Disaster Preparedness; Covid19

\begin{abstract}
Nurses have a role to take part in disaster situations. The development of a theoretical for disaster nursing is very much needed, but there are not many articles that discuss disaster nursing. This can happen because the nature of disasters experienced by humans cannot be predicted when they will occur and Health professionals need to concentrate on these activities. There have not been many in-depth studies related to how prepared nurses are in dealing with disasters, given their important role, especially in providing physical and psychological handling and assistance to victims when a disaster occurs. The COVID-19 pandemic situation as it is now is also a challenge for health workers, especially nurses. This study was conducted to determine the relationship between knowledge and nurse readiness in disaster preparedness through the 8 dimensions contained in the Emergency Preparedness Information Questionnaire (EPIQ) for nurse readiness in disaster preparedness, and 40 questionnaires for knowledge about disasters. The sample is a nurse in a hospital, active in disaster activities, aged 21-60 years, and willing to become research respondents. The total number of nurses is 66 people. The data collection technique was carried out on all nurses who worked and were active in disaster activities at the PKU Muhammadiyah Hospital in Kebumen. Data was taken through an online recap and analyzed using SPSS 25. The results showed average knowledge is 61.4 with Std Dev 12.97 (38-88) and Nurse readiness 76.4 with Std Dev 6.62 (61-89). The results of the Pearson correlation test showed that there was a relationship between knowledge and nurse readiness in disaster preparedness $(p=0.000)$. Massive and continuous education process will improve nurses' preparedness in dealing with the COVID-19 disaster.
\end{abstract}

This work is licensed under a Creative Commons Attribution 4.0 International License.

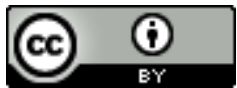

Corresponding Author:

Putra Agina Widyaswara Suwaryo

Faculty of Health Science, Universitas Muhammadiyah Gombong

Yos Sudarso Street, 461 Gombong

Email: putra@unimugo.ac.id

\section{INTRODUCTION}

Disasters not only affect the system of institutional arrangements but also affect the people in the community. Nurses have a role to take part in disaster situations. The development of a theoretical framework for disaster nursing is very necessary, but there are not many articles that discuss disaster nursing [1]. This can happen because the nature of disasters experienced by humans cannot really be predicted when they occur and Health professionals need to concentrate on these activities [2].

The scope of disaster nursing covers various aspects of life, such as parents, adults, children and so on. Expertise in this field needs further investigation in the context of disaster nursing [3]. Measuring preparedness in disaster care areas is an important concept and requires continuity. Systematic health services need to be carried out to improve disaster preparedness. The establishment of a set of core competencies for disaster nursing that is made specifically for the community, is the first step in preparing nurses to deal with disaster situations [4]. 
Nurses are the first to provide help when there are victims who experience problems such as accidents outside the hospital [5], [6]. The competence of nurses has a wider scope, where they must be able to care for victims and have the skills to prevent worsening of conditions in patients outside the hospital [7]. The process of moving or evacuating is also carried out by medical personnel who must synergize between health services, so that there is no overlap and patient overload in health services.

Knowledge is the result of knowing and this occurs after people have sensed a certain object. Knowledge is a very important domain to shape behavior. Nurses as the largest health workers and first responders and service providers in disaster emergency response are required to have higher disaster preparedness than other teams. The ability of nurses in disaster management preparedness must be supported by a good knowledge base and attitude in disaster management. Disaster management planning requires principles where one of the things that must be possessed is the right knowledge.

The most suitable disaster management to reduce disaster risk is in the pre-disaster stage. This is in accordance with the change in the concept of disaster management which previously focused on disaster emergency response efforts, currently optimizing efforts at the pre-disaster stage, namely preparedness. Preparedness is part of the activity that shows the level of effectiveness of the response to a disaster as a whole.

The key role of nurses can be reflected in disaster management, namely during pre-disaster, during disaster, and post-disaster. A nurse's preparedness can minimize the impact of a disaster. Help for disaster victims starts from the pre-hospital emergency care stage, hospital stage, and rehabilitation. The Covid-19 pandemic is still ongoing, even the number of confirmed COVID-19 victims is increasing day by day. Data as of January 16, 2021, the number of confirmed COVID-19 patients in Central Java was 103 thousand cases, with 4,485 deaths. Health workers are also included in the high number of deaths (Central Java, 2021). During a disaster response, people will tend to be in close proximity (cramped) either due to limited space, such as an evacuation site, or to get a sense of security and comfort. This is certainly a challenge in itself when carrying out disaster evacuations during the Covid-19 pandemic situation.

The Health Team or Health cluster in Kebumen has been formed since 2018. Its role is very important when a disaster occurs. The Health Cluster consists of doctors, nurses, pharmacists and medical records with a total of 78 people. This Health Kluter is tasked with providing medical treatment to victims when a disaster occurs, which consists of all health facilities in Kebumen. This study was conducted to determine the relationship between the level of knowledge and the readiness of nurses in disaster preparedness during the COVID-19 pandemic.

\section{RESEARCH METHOD}

This study uses a descriptive correlative research method. This study identifies the knowledge and readiness of nurses in disaster preparedness through the 8 dimensions contained in the Emergency Preparedness Information Questionnaire (EPIQ). Sampling used a total sampling technique, with the criteria of active nurses in PKU Muhammadiyah Hospitals throughout Kebumen, active in disaster activities, aged 21-60 years and willing to be research respondents. The total number of nurses is 66 people. The questionnaire has been tested for validity and reliability to 10 nurses at PKU Muhammadiyah Gombong Hospital $r=0.910$ with significance $<0.05$ and alfa Cronbach 0.817 . The questionnaire consists of knowledge related to disasters and the role of nurses in disasters consisting of 40 multiple choice questions, of which 30 questions are disasters in general and 10 questions are disasters during the COVID-19 pandemic. While the nurse readiness questionnaire consists of 8 dimensions with a score range of 1-90, consisting of incident command systems, triage, epidemiology and surveillance, decontamination and quarantine isolation, communication, psychological problems, special populations and access to critical sources. The answers consist of never, have heard, know, are familiar and very familiar with the dimensions of nurse readiness

Validity test using bivariate Pearson correlation (product moment Pearson), the value of $r$ count $r$ table with sig 0.05 and is said to be valid. While the reliability test used the Cronbach alpha formula with an alpha value $>0.8$. As for the univariate analysis, the data will be presented in the form of figures and tables and then interpreted based on the data obtained. In the analysis of two variables using bivariate analysis to see the relationship between variables using the Pearson's test.

\section{RESULT AND DISCUSSIONS}

\subsection{Result}

Based on the results of research conducted on nurses at PKU Muhammadiyah Hospital throughout Kebumen, the subjects were 66 respondents. 
Table 1. Characteristics of Respondents

\begin{tabular}{|c|c|c|}
\hline Variabel & $\mathbf{n}$ & $\%$ \\
\hline \multicolumn{3}{|l|}{ Age } \\
\hline $21-30$ years & 7 & 10.6 \\
\hline $31-40$ years & 54 & 81.8 \\
\hline $41-50$ years & 2 & 3.1 \\
\hline $51-60$ years & 3 & 4.5 \\
\hline \multicolumn{3}{|l|}{ Sex } \\
\hline Male & 27 & 40 \\
\hline Female & 39 & 60 \\
\hline \multicolumn{3}{|l|}{ Education } \\
\hline Nursing Diploma & 39 & 60 \\
\hline Nurse Bachelor & 27 & 40 \\
\hline \multicolumn{3}{|l|}{ Length of Working } \\
\hline$<1$ year & 10 & 15.2 \\
\hline $2-5$ years & 46 & 69.7 \\
\hline $6-10$ years & 5 & 7.6 \\
\hline$>10$ years & 5 & 7.6 \\
\hline \multicolumn{3}{|l|}{ Work Status } \\
\hline Permanent & 55 & 83.3 \\
\hline Contract & 4 & 6.1 \\
\hline apprenticeship & 7 & 10.6 \\
\hline \multicolumn{3}{|l|}{ Experience Learning } \\
\hline Not & 5 & 7.6 \\
\hline BT\&CLS & 58 & 87.9 \\
\hline Other & 3 & 4.5 \\
\hline
\end{tabular}

Table 2 Knowledge and Readiness of Nurses in Disaster Preparedness

\begin{tabular}{lcccccc}
\hline \multicolumn{1}{c}{ Variabel } & Mean & Median & Std Dev & Min-Max & r & p \\
\hline Knowledge & 61.46 & 61.5 & 12.97 & $38-88$ & \multirow{2}{*}{0.670} & \multirow{2}{*}{0.000} \\
\hline Nurse Readiness & 76.45 & 76.5 & 6.62 & $61-89$ & & \\
\hline
\end{tabular}

\subsection{Discussion}

The results showed that the most nurses were in the age range of 31-40 years and dominated by 39 women. Nurses have a duty to provide excellent service and meet the needs of patients, especially those who are dependent. In addition, the nursing profession is a profession that is considered more suitable for women where the sense of caring is higher than men. Health service duties are carried out in a flexible manner where gender differences are still visible, for example when bathing patients, lifting jobs and so on. This also happens because of the cultural and moral values that are believed by the community. From the service side, some patients also think that women are more flexible in carrying out their duties as nurses [2], [8].

In addition, the last education of nurses is also many who are still diploma nursing. This is related to the policies of their respective workplace institutions which still accept and allow nurses with diploma nursing education to provide nursing services and care to patients, this is also still protected by law, including Law No. 38 of 2014 concerning Nursing Services. This proves that there is a need for a role from all parties to increase the knowledge of nurses, where one of the functions of education is the best media to prepare everything, especially those related to disasters [9].

Nurses have a high sense of caring if they often provide services to patients, it is proven that the most respondents have 2-5 years of work and the working status is 55 people. The longer a nurse works, the more experience she gains and will increase work productivity in disaster preparedness. BTCLS (Basic Trauma and Cardiac Life Support) training is a basic training that must be possessed by nurses, not only in emergency or critical rooms, but also in other rooms [10]. This is a mandatory requirement that must be possessed, so that almost all respondents have a BTCLS training certificate. Those who don't have it because they haven't been updated with the latest BTCLS training and still have the old certificate, namely Basic Trauma and Cardiac Life Support (BT\&CLS). Training is one way to increase knowledge for nurses in disaster management before, during and after a disaster [11]. 
Educational results obtained the average knowledge of nurses about disasters is 61.46. Nurses need to have knowledge about disaster preparedness. This is because everything related to medical aid and equipment must be done properly. In addition, knowledge is also the basis for providing health services. Lack of knowledge will affect the speed and accuracy in providing optimal services, especially in urgent situations during disaster emergency response [12]. The results of the analysis Most nurses, namely women, have good knowledge, this is because female nurses tend to be more thorough, diligent and active in learning, so they have better knowledge. Education also affects knowledge, this is evidenced by the number of nurses with a professional education background (ners) having better knowledge [13].

The results also showed that the average preparedness of nurses in disaster preparedness was 76.45 . The results of the analysis prove that nurses are good in the dimensions of triage and communication in disasters, but need to be improved in the dimensions of the command and detection system of biological agents. All dimensions of the disaster preparedness questionnaire by medical personnel, namely nurses, are very important, so they must be known by the Health team when conducting and providing disaster services to the community.

The results of the correlation test showed that the knowledge of nurses had an influence on the readiness of nurses in disaster preparedness $(\mathrm{p}=0.000)$. This is also explained by Indri, et al $(2020)$, that knowledge has the most important role in the early stages before someone does or applies the results he knows as a form of proof of the knowledge itself. Knowledge also has a significant impact on a person's consciousness which later forms character and habits.

\section{CONCLUSION}

Characteristics of respondents are at most 31-40 years old with a D3 nursing education background which is dominated by women and 2-5 years of work. Training attended by BTCLS and working status as a permanent employee. The average knowledge of nurses related to disaster is 61.46 The average preparedness of nurses in disaster preparedness is 76.45. There is an influence between knowledge on the readiness of nurses in disaster preparedness. There is a need for counseling and disseminating information related to disasters, especially for medical personnel, namely nurses. In addition, it is necessary to introduce the latest updates in disaster management that focus on disaster risk reduction in health services to the community, as well as follow-up research with a wider impact on disaster risk reduction specifically for medical nurses or health clusters.

\section{Acknowledgements}

Thank you to Allah SWT, both parents and all comrades in arms who have helped from beginning to end. Then, thanks to Head of LPPM University of Muhammadiyah Gombong has facilitated the implementation of research until publication, the MDMC medical team is willing to be a research respondent.

\section{REFERENCES}

[1] H. J. Triyana, "Indonesian compliance and its effective implementation of international norms on disaster response," in Humanitarian Action: Global, Regional and Domestic Legal Responses, 2014.

[2] D. Alfred et al., "Preparing for disasters: Education and management strategies explored," Nurse Educ. Pract., vol. 15, no. 1, pp. 82-89, Jan. 2015, doi: 10.1016/J.NEPR.2014.08.001.

[3] S. Baack and D. Alfred, "Nurses' preparedness and perceived competence in managing disasters," $J$. Nurs. Scholarsh., 2013, doi: 10.1111/jnu.12029.

[4] N. Ahayalimudin and N. N. S. Osman, "Disaster management: Emergency nursing and medical personnel's knowledge, attitude and practices of the East Coast region hospitals of Malaysia," Australas. Emerg. Nurs. J., vol. 19, no. 4, pp. 203-209, Nov. 2016, doi: 10.1016/J.AENJ.2016.08.001.

[5] B. Kalanlar, "Effects of disaster nursing education on nursing students' knowledge and preparedness for disasters," Int. J. Disaster Risk Reduct., vol. 28, pp. 475-480, Jun. 2018, doi: 10.1016/J.IJDRR.2017.12.008.

[6] W. C. Tzeng et al., "Readiness of hospital nurses for disaster responses in Taiwan: A cross-sectional study," Nurse Educ. Today, 2016, doi: 10.1016/j.nedt.2016.02.025.

[7] L. J. Labrague et al., "Disaster preparedness among nurses: a systematic review of literature," International Nursing Review. 2018, doi: 10.1111/inr.12369.

[8] T. F. Fathani, D. Karnawati, and W. Wilopo, "An integrated methodology to develop a standard for landslide early warning systems," Nat. Hazards Earth Syst. Sci., 2016, doi: 10.5194/nhess-16-21232016.

Proceeding homepage: https://conferenceproceedings.ump.ac.id/index.php/pshms/issue/view/10 
[9] P. F. Hanes, "Wildfire Disasters and Nursing," Nursing Clinics of North America. 2016, doi: 10.1016/j.cnur.2016.07.006.

[10] T. Zulyadi, "Community Empowerment in Disaster Risk Reduction," Online), 2017.

[11] R. M. Adams, B. Karlin, D. P. Eisenman, J. Blakley, and D. Glik, "Who Participates in the Great ShakeOut? Why Audience Segmentation Is the Future of Disaster Preparedness Campaigns," International Journal of Environmental Research and Public Health, vol. 14, no. 11. 2017, doi: 10.3390/ijerph14111407.

[12] C. H. Chi, W. H. Chao, C. C. Chuang, M. C. Tsai, and L. M. Tsai, "Emergency medical technicians' disaster training by tabletop exercise," Am. J. Emerg. Med., vol. 19, no. 5, pp. 433-436, 2001, doi: 10.1053/ajem.2001.24467.

[13] W. Adiyoso and H. Kanegae, "Tsunami-Resilient preparedness index (TRPI) as a key step for effective disaster reduction intervention," in Sustainable Future for Human Security: Society, Cities and Governance, 2017. 